\title{
A DECADE OF UNMANNED AERIAL SYSTEMS IN IRRIGATED AGRICULTURE IN THE WESTERN U.S.
}

\author{
J. L. Chávez, A. F. Torres-Rua, W. E. Woldt, H. Zhang, C. Robertson, \\ G. W. Marek, D. Wang, D. M. Heeren, S. Taghvaeian, C. M. U. Neale
}

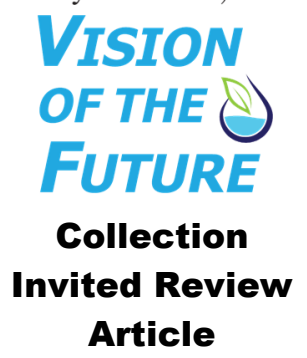

HighLights

- Unmanned aerial systems (UAS) are able to provide data for precision irrigation management.

- Improvements are needed regarding UAS platforms, sensors, processing software, and regulations.

- Integration of multi-scale imagery into scientific irrigation scheduling tools are needed for technology adoption.

\begin{abstract}
Several research institutes, laboratories, academic programs, and service companies around the United States have been developing programs to utilize small unmanned aerial systems (sUAS) as an instrument to improve the efficiency of in-field water and agronomical management. This article describes a decade of efforts on research and development efforts focused on UAS technologies and methodologies developed for irrigation management, including the evolution of aircraft and sensors in contrast to data from satellites. Federal Aviation Administration (FAA) regulations for UAS operation in agriculture have been synthesized along with proposed modifications to enhance UAS contributions to irrigated agriculture. Although it is feasible to use sUAS technology to produce maps of actual crop coefficients, actual crop evapotranspiration, and soil water deficits, for irrigation management, the technology and regulations need to evolve further to facilitate a successful wide adoption and application. Improvements and standards are needed in terms of cameras' spectral (bands) ranges, radiometric resolutions and associated calibrations, fuel/power technology for longer missions, better imagery processing software, and easier FAA approval of higher altitudes flight missions among other issues. Furthermore, the sUAS technology would play a larger role in irrigated agriculture when integrating multi-scale data (sUAS, groundbased or proximal, satellite) and soil water sensors is addressed, including the need for advances on processing large amounts of data from multiple and different sources, and integration into scientific irrigation scheduling (SIS) systems for convenience of decision making. Desirable technological innovations, and features of the next generation of UAS platforms, sensors, software, and methods for irrigated agriculture, are discussed.
\end{abstract}

Keywords. Agricultural water management, Irrigation prescription mapping, Irrigation scheduling, Precision irrigation, Remote sensing, Sensors, Spatial crop evapotranspiration, Unmanned aerial systems. (c) (1) (5) $\bigodot_{\mathrm{BY}}^{\text {TC }}$ The authors have paid for open access for this article. This NonCommercial-NoDerivatives 4.0 International License https://creative commons.org/licenses/by-nc-nd/4.0/

Submitted for review in January 2020 as manuscript number NRES 13941; approved for publication as an Invited Review Article part of the NIS Collection by Natural Resources \& Environmental Systems Community of ASABE in May 2020.

Mention of company or trade names is for description only and does not imply endorsement by the USDA. The USDA is an equal opportunity provider and employer.

The authors are José L. Chávez, Associate Professor and Extension Irrigation Specialist, Colorado State University, Fort Collins, Colorado; Alfonso F. Torres-Rua, Assistant Professor, Utah State University, Logan, Utah; Wayne E. Woldt, Associate Professor, Biological Systems Engineering and School of Natural Resources, University of NebraskaLincoln, Lincoln, Nebraska; Huihui Zhang, Research Scientist, USDAARS, Fort Collins, Colorado; Christopher Robertson, Director of Colorado State University Drone Center, Fort Collins, Colorado; Gary W. Marek, Research Agricultural Engineer, USDA-ARS, Bushland, Texas; Dong Wang, Research Leader, USDA-ARS, Parlier, California; Derek M. Heeren, Associate Professor and Irrigation Engineer; Saleh Taghvaeian, Associate Professor and Extension Specialist, Oklahoma State University, Stillwater, Oklahoma; and Christopher M. U. Neale, Director of Research, Daugherty Water for Food Global Institute, University of Nebraska, Lincoln, Nebraska. Corresponding author: José L. Chávez, 1372 Campus Delivery, Fort Collins, CO 80523; phone: 970-491-6095; e-mail: jose.chavez@colostate.edu.

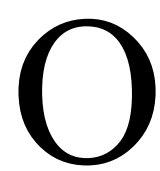

ver several decades, different space-borne platforms (satellites) and sensors have been evaluated for their use in agriculture and agricultural water management. For example, remote sensing (RS) information was used to identify crops grown during different seasons, to estimate crop biophysical characteristics [such as canopy height $\left(\mathrm{h}_{\mathrm{c}}\right)$, biomass, and leaf area index (LAI)], and to determine crop water use or actual crop evapotranspiration $\left(\mathrm{ET}_{\mathrm{a}}\right)$, among other parameters for irrigation management. Originally, images from NASA satellites such as the Moderate Resolution Imaging Spectroradiometer (MODIS), aboard the Terra (originally known as EOS AM-1) and Aqua (originally known as EOS PM-1) satellites, were used. However, MODIS pixel spatial resolution of $500 \mathrm{~m}$ for the visible (VIS) and near infra-red (NIR) bands, and 1,000 $\mathrm{m}$ for the thermal infrared (TIR) bands, are not adequate for most applications on agricultural parcels and field sizes in the United States or the world. Later, multispectral images from satellites Landsat 5, 7, and 8 (30-120 $\mathrm{m}$ spatial resolution) were used to map vegetation conditions 
and $\mathrm{ET}_{\mathrm{a}}$ using different algorithms. However, Landsat satellites have a fixed revisit frequency of 16 days; which is not enough to monitor the rapid crop growth and water use in irrigated agriculture. Other more recent satellites such as Sentinel-2 and Dove (from Planet) do not carry a thermal sensor necessary for the application of energy balance algorithms and $\mathrm{ET}_{\mathrm{a}}$ estimation. These constraints limit the application of satellites to generate frequent ET maps (e.g., several times per week) to be used in soil water balance methods to schedule irrigation more efficiently and better manage scarce water resources. As an alternative, Unmanned Aerial Systems (UAS) have been developed (Gonzalez Toro and Tsourdos, 2018; Avtar and Watanabe, 2020) and introduced for improving the efficiency of production agriculture (Woldt et al., 2014), with an emphasis on irrigated agriculture to allow higher spatial and temporal resolution maps of crop biophysical properties, soil water, crop water use, nutrients, etc. The operational flexibility of airborne remote sensing platforms allows the rapid deployment of these platforms in response to changing weather conditions and/or data requirements. The ability to adjust the overpass timing and frequency with these airborne systems is a significant advantage over the satellite remote sensing (RS) platforms. Not only can data collection occur when the weather allows it (e.g., cloud free, calm winds), but also the ability to fly more frequently allows for greater accuracy in soil water content (SWC) or deficit (SWD) estimation when using RS of $\mathrm{ET}_{\mathrm{a}}$ algorithms. The ability to vary flight characteristics of an airborne remote sensing platform is another benefit over satellite platforms. By adjusting the flight parameters (e.g., flight speed and altitude), the spatial resolution of the imagery can be adjusted to meet the information requirements to adequately describe the conditions of the planted crop (e.g., multiple crop settings). The UAS technology is continuously evolving, driven by the demand of the end users (producers), researchers, and manufacturers (Woldt et al., 2016a; 2016b; 2016c). UAS are not sufficiently mature to be operationally used in irrigation management and farming activities. Still, several technological, regulatory and research limitations need to be overcome.

In that context, this article discusses the different technologies, methods, regulations, constraints, and challenges faced by sUAS in the last decade in different regions of the United States with a focus on the Western United States where irrigated agriculture is challenged by water availability. Desired UAS innovations and regulatory opportunities in the near future are suggested.

\section{RESEARCH METHODS}

In this section, a brief description of UAS platforms and sensors (cameras) used in irrigated agriculture are presented. Several publications in the literature describe in depth the variety of UAS platforms existing for a wide array of agricultural applications. For in depth information on UAS technologies readers are directed to material published in Avtar and Watanabe (2020), Gonzalez Toro and Tsourdos (2018), Sankaran et al. (2015). Furthermore, this section includes a presentation of different algorithms used to estimate crop water use, soil water deficit, as well as a summary of current Federal Aviation Administration (FAA) regulations.

\section{UAS TeChNOLOGY - Platforms}

UAS platforms used in agriculture weigh around 2.3 to $11.3 \mathrm{~kg}$ (5 to $25 \mathrm{lb}$ ) and are comprised of fixed wing, multirotor, and a mix of the two called Vertical Take Off and Landing (VTOL) platforms. These platforms are also referred as "small UAS" or sUAS. Fixed-wing UAS can collect imagery continuously for a period of about 30 to $45 \mathrm{~min}$ depending on weather and battery conditions; while multirotor UAS battery lasts about 15 to $30 \mathrm{~min}$. The next generation of UAS, called provisionally "large fixed-wing" will combine the characteristics of multirotor and fixed-wing UAS for takeoff / landing in narrow areas (e.g., service roads), longer endurance ( 2 to $3 \mathrm{~h}$ flight) and heavier payload $(2.3+\mathrm{kg}$ or $5+\mathrm{lb})$ for complex, multi sensor payload and computational capabilities on board. The progress in the development and availability of UAS technologies in the market is mostly driven by agency regulations [in the US FAA flight ceiling of $122 \mathrm{~m}$ (400 ft) above ground level (AGL), line of sight of $1,287 \mathrm{~m}$ (0.8 miles) radius, with expected changes in regulation that will allow for further development of versatile UAS platforms].

\section{UAS TECHNOLOGY - SENSORS}

UAS payload includes a variety of sensors; as optical sensors (e.g., photographic RGB camera, broadband multispectral cameras [mainly green $(\mathrm{G})$, red $(\mathrm{R})$, red-edge $(\mathrm{Re})$, and near infra-red (NIR) bands], and narrowband hyperspectral cameras), infrared thermal cameras, Light Detection And Range (LiDAR), and more recently L-band radar technology (e.g., Lobe Differencing Correlation Radiometer or LDCR). Depending on flight altitude (maximum of $122 \mathrm{~m}$ (400 ft) without an FAA exemption), UAS multispectral sensors' pixel spatial resolution can range between 2.5 and $8 \mathrm{~cm}(1-3$ in.) depending on flight altitude and camera field of view (FOV). The spatial resolution of thermal cameras is coarser in relation to that of multispectral cameras (generally half of optical cameras), up to 16 times (e.g., Altum camera with $80 \mathrm{~cm}$ thermal pixel resolution and approximately $5 \mathrm{~cm}$ optical pixel resolution, at $122 \mathrm{~m} \mathrm{AGL)} \mathrm{the} \mathrm{optical} \mathrm{resolution}$ (for the same flight altitude of multispectral cameras). Custom camera payloads in research groups can take advantage of exchange of spectral filters, increased resolution (optical and thermal), although the initial investment is significantly higher than commercially available UAS cameras. One restriction on UAS sensors is the lack of standards for the radiometric response of the different bands, being a manufacturer choice rather than a scientific based design. The differences in cameras' radiometric characteristics introduce a technological bias for comparison and replication of studies with UAS, being thermal sensors the most affected by the nonexistence of radiometric standards (Torres-Rua, 2017; Torres-Rua et al., 2018; Torres-Rua et al., 2019;).

When using UAS, preflight planning is required prior to heading to the field site. Airspace class and proximity to airports of the proposed flight area must be checked. When appropriate, permissions and/or notifications to use airspace must be secured/given prior to missions. Waypoint missions 
of the study site are built beforehand to allow downtime between flights to be minimized and allow data collection to occur in optimum temporal windows (e.g., wind, solar incidence angle, crop water status). A fundamental aspect of mission planning involves image overlap. This affects the number of images acquired, area covered within the sensor field of view, flight elevation above ground level, flight velocity, etc. Guidelines and discussions on image overlap can be found in Seifert et al. (2019).

\section{IMAGERY Processing SOFTWARE}

In order to obtain multichannel ortho-mosaics of surface reflectance, temperature, and 3D products, that are geo-referenced and corrected for geometric errors and light distribution, specialized software are used. Briefly, specialized software are used to convert the imagery digital numbers acquired to meaningful surface reflectance and temperature values. To do so, several intermediary steps are needed. For instance, correction of camera lens-vignetting effects, pixel geometric radial distortions, individual band (geo) registration (to a basemap and to each other) and stacking, imagery mosaicking, digital numbers conversion to radiance, absolute calibration, etc. Further details can be found in Maguire (2018a), Hathaway (2016), and Chávez et al. (2005). Typical software use to manipulate raw imagery acquired with UAS include: AgiSoft Photoscan, Pix4D, ESRI ArcGIS 10.4 (ESRI, Redlands, Calif), and open source software. The geoprecision of the software derived products is limited to the accuracy of the UAS onboard GPS and the existence of Ground Control Points (GCP). On-board GPS are still limited in accuracy $( \pm 3 \mathrm{~m})$ reducing its usability in row crops and orchards, while for extensive crops (corn, small grains and others), the accuracy of the onboard seems adequate for most agricultural applications.

\section{Algorithms USED to Estimate ACTUAL Crop EVAPOTRANSPIRATION (ET $\left.{ }_{\text {a }}\right)$}

According to Trout and Johnson (2007), Gowda et al. (2008), Chávez et al. (2012), Neale et al. (2012), and Han et al. (2018), there are four major types of $\mathrm{ET}_{\mathrm{a}}$ algorithms used with data from UAS. These methods include: a) algorithms based on reference ET ( $\left.\mathrm{ET}_{\text {ref }}\right)$ and updated crop coefficients with vegetation indices obtained from combination of multispectral bands (mainly Red and NIR bands); b) land surface energy balance methods that require RS data from multispectral and thermal bands; c) a combination of these two methods (a) and (b) in the so called "hybrid" approach; and d) the crop water stress index (CWSI) approach based on $\mathrm{ET}_{\text {ref }}$ and a stress index based on vegetation canopy temperature (using TIR data). One software that has been used for processing imagery from unmanned aircraft is the Spatial EvapoTranspiration Modeling Interface (SETMI; Geli and Neale, 2012; Neale et al., 2012; Barker et al., 2018a). The software calculates $\mathrm{ET}_{\mathrm{a}}$ using a hybrid methodology combining a reflectance-based crop coefficient approach (Neale et al., 1989) using multispectral data and a two-source energy balance approach using thermal imagery, and was modified to maintain a spatial soil water balance (Barker et al., 2018a, b). For real time irrigation management, the model was initially used with Landsat satellite imagery (Barker et al., 2018b, 2019), but was later used with imagery from unmanned aircraft systems (Bhatti et al., 2020). Soil water measurements at multiple locations in the field have been needed for ground truth for the soil water balance; however, ongoing improvements in SETMI are reducing the amount of drift in the soil water balance when unaided by soil water measurements (Barker et al., 2019). While many unmanned aircraft systems adequately capture spatial patterns in the crop canopy, a challenge for calculating $\mathrm{ET}_{\mathrm{a}}$ with unmanned aircraft imagery is the need for a high level of accuracy in the data (Barker et al., 2020), which has been a greater challenge for thermal imagery than multispectral imagery (Maguire, 2018). Compared to Landsat imagery, unmanned aircraft systems provide more frequent imagery and allow SETMI to be executed on a finer spatial scale (Bhatti et al., 2020). Several other algorithms have been used for estimation of $\mathrm{ET}_{\mathrm{a}}$, such as vegetation-based NDVI (Morandé et al., 2020), and satellite-based surface energy balance, have been translated to sUAS (or Unmanned Aerial Vehicles, UAV) characteristics, such as the "Mapping Evapotranspiration at High Resolution with Internalized Calibration" or METRIC (Allen et al., 2007; Morandé et al., 2020), and the "TwoSource Energy Balance" or TSEB (Nieto et al., 2019) models. In addition, another approach that potentially could be applied to sUAS data is that by Dhungel et al. $(2019,2020)$; where they provide evidence that the direct application of the surface energy balance equation can be adequate to quantify flux components, including separation of Evaporation and Transpiration rates. Still, a current challenge remains regarding the integration and evaluation of multiple remote sensing based $\mathrm{ET}_{\mathrm{a}}$ approaches towards operational application in irrigation management.

\section{FAA REgUlations SUMMARY}

FAA regulations have been evolving in the last decade, starting in a disorganized manner and evolving to what is known now as Part 107 (Remote Pilot Certification for commercial flight operations), Certificates of Waiver or Authorization (COA) or Exemptions under Section 44807. Part 107 is the main set of federal aviation regulations that govern UAS technology development and research/commercial applications of UAS in agriculture in the United States, and many countries that replicate the U.S. regulations. COAs are special permissions to test and explore technologies within the context of civil flight operations, and exemptions under Section 44807 provide for flight operations that are beyond Part 107 within the context of commercial flight operations. COAs and Section 44807 exemptions are important because they provide a mechanism to conduct flight operation on systems that may become mainstream at some point in time (Woldt et al., 2015). In agriculture, certain research groups (e.g., CSU Drone Center, AggieAir, UC Merced, and NUAIRE) have been using COAs or waivers to explore higher elevation ceilings $[\sim 411 \mathrm{~m}(1,350 \mathrm{ft})$ above ground level or AGL], flights at night to collect thermal information, and deployment of Remotely Piloted Aerial Application Systems (RPAAS). Other FAA regulations to consider include: 
- Must have a sUAS Remote Pilot Certificate issued by the FAA to fly UAS for commercial and civil purposes, or operate under the auspices of a COA. Most work for precision agriculture or research would be considered either a commercial or civil operation, depending on the status of the UAS owner.

- $\quad$ sUAS must weigh under $22.6 \mathrm{~kg}(55 \mathrm{lb})$, unless exempted by the FAA under COAs or 44807 exemption.

- Weather visibility of at least 3 miles $(4.8 \mathrm{~km})$, and a maximum speed of $44.8 \mathrm{~m} / \mathrm{s}$ ( 87 knots).

- Cannot fly at night without a waiver from the FAA.

- Cannot fly over people unless they are directly involved in the operation.

- Must stay below $122 \mathrm{~m}$ (400 ft) AGL. This presents challenges for agriculture flights due to sensor reset time/UAS speed. It also prevents from mapping larger areas where high pixel spatial resolution is not needed. Waivers for higher altitudes are very difficult to receive and take up to 4-6 months to be approved, if they are.

- Cannot fly in any controlled airspace without authorization. It is becoming easier to receive authorization through the "Low Altitude Authorization and Notification Capability" (LAANC) system.

- Cannot carry hazardous material on the sUAS. This would pertain to UAS sprayers for fertilization and pest control, unless flying under the auspices of a COA.

- The sUAS must be registered with the FAA.

- The minimum qualification age for a remote pilot certificate is 16 years, and earning a passing score on the Part 107 Knowledge Exam. Operations in Class G airspace are permitted without permission from Air Traffic Control (ATC). Operations are possible in Class B, C, D, and E airspace with prior approval of ATC. An illustration of the different airspace designations can be found in FAA (2020).

- The UAS must be flown within Visual Line Of Sight (VLOS) at all times. This is a hurdle to large-scale agriculture research flights as the pilots continually must relocate to maintain VLOS when operating in large area. Additionally, it does not allow for programmed autonomous crop inspection UAS systems to be operated on agricultural sites. UAS systems are needed that could autonomously fly pre-program routes and deliver data to farmers in a manner that requires little or no operator input. In a manner similar to an increase in the maximum ceiling for UAS flights, relieving the requirement to keep the UAS within line if sight for agricultural flight operations, has the potential to increase adoption of UAS for irrigation management.

While the Part 107 approach to UAS regulation has met a degree of reasonable success, there are emerging regulations on the horizon that have the potential to impact agricultural use of UAS. The FAA has recently published a Notice of Proposed Rule Making (FAA NPRM, 2019), that will mandate a Remote Identification system (RID) for all
UAS. If UAS are not able to meet the new standard, they could only fly in specific geographic areas that are specially designated for them. The proposed RID will have two categories of remote ID: standard and limited. Standard category will require a UAS to broadcast its identification and location, and simultaneously send that information to a UAS service supplier. The limited category would mean that the UAS could send information via the internet only (i.e., no broadcast capability), but these UAS would need to operate no more than $130 \mathrm{~m}$ from their control station. Cell phonetype technology is the primary approach that is being proposed for this RID, in which UAS pilots will need a data plan to handle the communications.

\section{UAS FIELd STUdIES FindingS}

This section presents results on research, development and services of UAS for irrigation water management from some western states in the United States.

\section{CALIFORNia}

\section{USDA-ARS - Parlier}

In collaboration with the Mechatronics, Embedded Systems and Automation (MESA) Lab at the University of California Merced, sUAS were used at three long-term field experiments at the USDA-ARS, San Joaquin Valley Agricultural Sciences Center at Parlier, California. The first experiment was an irrigation study where pomegranate trees were planted in 2010 in a 1.3 ha orchard and irrigated with surface drip at $100,75,50$, and $35 \%$ rates. The $100 \%$ rate corresponded to full replacement of crop evapotranspiration $\left(E T_{c}\right)$ measured with an in-situ weighing lysimeter. Each irrigation treatment was repeated four times with 45 trees per treatment per replication and a total of 809 trees in the orchard. The main goal was to determine pomegranate irrigation requirement, crop coefficient, and effect of deficit irrigation on crop response. The second experiment was a nectarine irrigation study where nectarine scions were budded with a peach root stock in 2015 in a 1.7 ha orchard and irrigated with surface drip, microsprinkler, and furrow methods at $100 \% \mathrm{ET}_{\mathrm{c}}$. A Bowen ratio (BR) system was installed in the orchard for in-situ measurement of $\mathrm{ET}_{\mathrm{a}}$. The drip and microsprinkler irrigation each had five sub-treatments and furrow had two sub-treatments. Each irrigation treatment was repeated six times with 24 trees per treatment per replication and a total of 1,728 trees in the orchard. The objective was to evaluate effect of methods of irrigation on the establishment of the budded nectarines. The third experiment was a biochar-irrigation study where a dehydrator onion crop was planted in 2015, 2016, and 2017 and a processing tomato crop was used in 2018 and 2019 in a 0.4 ha field plot and irrigated with surface drip at 100,75 , and $50 \%$ rates. The $100 \%$ rate corresponded to maintaining soil water content above $22 \%$ by volume in the crop root zone measured with in-situ soil water content sensors. Each irrigation treatment was superimposed over four biochar treatments and repeated three times and a total of 12 treatments and 36 sub plots were used in the experiment. The main focus of the study was to determine effect of soil biochar amendments and potential 
interactions with irrigation rates on crop response. A Hover quadcopter (four rotors), equipped with a Pixhawk flight controller, GPS, and telemetry antennas, was used as the sUAS platform for these studies. Multispectral images were collected using the Survey2 (MAPIR, San Diego, Calif.) cameras with four bands: Blue, Green, Red (RGB) and Nearinfrared (NIR). The MAPIR camera has a resolution of 4608 $\times 3456$ pixels, with a spatial resolution of $1.01 \mathrm{~cm} /$ pixel when the UAS flew at $30 \mathrm{~m}$ above the ground. The Survey 2 cameras have a faster interval timer, 2 seconds for JPG mode, and 3 seconds for RAW + JPG mode. Faster interval timer would benefit the overlap design for UAS flight missions, such as reducing the flight time, enabling higher overlapping. Thermal images of the crop canopies were collected using the ICI 9640 P-Series (ICI, Beaumont, Tex.) camera. The thermal camera has a resolution of $640 \times 480$ pixels and a spectral band in the range 7 to $14 \mu \mathrm{m}$. A Raspberry $\mathrm{Pi}$ Model B computer was used to trigger the thermal cameras during the flight missions. During each growing season, the UAS was flown bi-weekly over these research plots near solar noon. The images of a color panel were taken right before and after the flight missions, servicing as the reflectance reference for the Survey2 cameras. Containers filled with icewater were placed in the research plots during the flight missions to serve as references for the thermal camera. Preliminary results indicated that pomegranate canopy could be classified at the pixel level using a convolutional neural network approach, termed instance-aware semantic segmentation, with a 90\% accuracy (Zhao et al., 2018a, 2018b). This is important because accurate estimation of canopy size and canopy characteristics is valuable for crop management. For the biochar-irrigation experiment, thermal images could provide adequate delineation of irrigation treatment $\left(\mathrm{R}^{2}=0.79\right)$. Addition of the optical and NIR images further improved the accuracy of irrigation treatment estimation as responses in crop water status $\left(\mathrm{R}^{2}=0.84\right)$ (Niu et al., 2019). These preliminary findings indicate the strong potential for using small UASs for irrigation management in arid or semi-arid environments.

\section{Colorado \\ Colorado State University}

At Colorado State University (CSU), sUAS development and research started in 2015. The CSU sUAS was designed to collect optical imagery in the red $(R)$ and green $(G)$ bands, as well as in the NIR and TIR bands of the electromagnetic spectrum. The objective of the study was to integrate multispectral RS cameras into a commercially available UAS for research of spatially distributed $\mathrm{ET}_{\mathrm{a}}$ at very high spatial resolutions. The aircraft chosen, at the time, was the fixed-wing Tempest (UASUSA, Inc., Longmont, Colo.). A commercially available platform was chosen because of its long operating range, stability, and payload capability. This fixedwing UAS was originally designed for flight operations in tornado-prone thunderstorms. The system was fully autonomous, with flight operations controlled through an on-board autopilot and also via radio control $(\mathrm{R} / \mathrm{C})$. The autonomous controls provided a stable platform required to collect good quality high resolution RS data. The UAS payload included a multispectral camera (ADC SNAP, Tetracam Inc., Chatsworth, CA) using a 1.3 Mega Pixel electronic global snap sensor that creates images consisting of $1280 \times 1024$ pixels (field of view $\mathrm{H} 37.67^{\circ}$ and $\mathrm{V} 28.75^{\circ}$ ), a thermal infrared camera (Tau 2, 640, FLIR, Wilsonville, Ore.) that creates images having $640 \times 512$ pixels with a field of view $\mathrm{H} 32^{\circ}$ and $\mathrm{V} \mathrm{26}$, and a digital RGB camera (SRL A6000 digital camera, Sony Global, Tokyo, Japan) displaying 24.3 Mega Pixels and an aspect ratio of $3: 2$. The system maximum takeoff weight was $9.5 \mathrm{~kg}$ (21 lb). The research location, in 2015, was the Linear-Move irrigated corn plots available at Colorado State University Agricultural Research Development and Education Center (CSU ARDEC), near Fort Collins, Colorado (CO), USA. During this initial UAS integration, some issues were encountered, as sensors not communicating well with the on-board autonomous control system, and the barometric pressure sensor/method, used to calculate flight altitude, not functioning properly (which defaulted to manual take off and landings). A TSEB ET algorithm was applied to the UAS at-sensor surface reflectance and temperature imagery to obtain $\mathrm{ET}_{\mathrm{a}}$ maps and through a SWB estimate SWD. Results revealed that the UAS-based ET $a$ values were relatively well estimated. An evaluation of derived SWD indicated that the error was relatively small (mean bias error (MBE) of $-2.45 \mathrm{~mm} / \mathrm{m}$ and root mean square error (RMSE) of $20.20 \mathrm{~mm} / \mathrm{m}$ ), Hathaway (2016) and Chávez (2017).

In 2017, a collaboration with USDA-ARS was initiated to further evaluate UAS technology and $\mathrm{ET}_{\mathrm{a}}$ methods to manage irrigation. An experiment was conducted on two corn fields. One field was deficit irrigated and the other was fully irrigated, at the Limited Irrigation Research Farm (LIRF), in Greeley, Colorado. The fields were subsurface drip irrigated (SDI) and the size of each field was $110 \mathrm{~m}$ (width) by $190 \mathrm{~m}$ (length). Flights were planned close to local noon as much as possible. The UAS airframe used was a multirotor DJI Spreading Wings S900 hexacopter (Da-Jiang Innovations Science and Technology Co., LTD, Shenzhen, China). The S900 frame weights $3 \mathrm{~kg}(6.6 \mathrm{lb})$ with a maximum takeoff weight of $8.2 \mathrm{~kg}(18 \mathrm{lb})$. The UAS system was powered by a MaxAmps 13500XL 6S 22.2v 13500mAh LiPo battery (MaxAmps, Spokane, Wash.). With airframe, battery, and cameras payload, the $\mathrm{S} 900$ weighed $5.8 \mathrm{~kg}$ (12.8 $\mathrm{lb}$ ), and was capable of flying continuously for about $13 \mathrm{~min}$. A 3DR Pixhawk PX4 flight controller (3D Robotics, Berkley, Calif.) was installed on the UAS. The PX4 features a $168 \mathrm{Hhz}$ Cortex M4f CPU with $256 \mathrm{~KB}$ of RAM and 2MB of flash memory. The PX4 also features 3D accelerometer, magnetometer, gyroscope, and barometer sensors. The PX4 was paired with a 3DR/Ublox GPS and compass module, and a LightWare SF11-C $120 \mathrm{~m}$ laser rangefinder. The payload for the multirotor UAS consisted of a FLIR Tau 2 LWIR (FLIR Systems, Inc., Wilsonville, Ore.), and a Tetracam Mini-MCA6 multispectral cameras (Tetracam Inc., Chatsworth, Calif.). The Tau2 contains a $640 \times 480$ pixels (0.3 mega pixel) image sensor and has a spectral range from 7.5 to $13.5 \mu \mathrm{m}$. The Mini-MCA6 featured a six-camera array, with each camera containing $1280 \times 1024$ pixels (1.3 mega pixel) image sensor. A band-pass filter is fitted to each of the six cameras with $10 \mathrm{~nm}$ bandwidth. The center 
wavelengths of filters used in the study were $860,720,680$, 570,530 , and $490 \mathrm{~nm}$. ET $\mathrm{a}$ was estimated using the surface reflectance base crop coefficient approach. That is, surface reflectance data from the RS systems were used to produce vegetation indices, which were inserted into linear regression equations to estimate the actual vegetation/crop coefficient $\left(\mathrm{K}_{\mathrm{ca}}\right.$, ratio of actual to potential transpiration). Estimates of $\mathrm{ET}_{\mathrm{a}}$ were evaluated with corresponding $\mathrm{ET}_{\mathrm{a}}$ values from a land surface energy balance (METRIC, Allen et al., 2007). In this study, it was found that using very high resolution UAS RS imagery, along with a reflectance based crop coefficient, it is possible to estimate actual crop transpiration for corn with acceptable accuracy $(1.2 \pm 4.5 \%$ error, for fractional vegetation cover between $70 \%-90 \%$, and larger error for lower percent cover), Chávez et al. (2018).

\section{Description of the "CSU Drone Center"}

The CSU Drone Center (https://www.research.colostate.edu/csudronecenter/) exists, since 2018, to support the research, education, service, and community engagement mission of Colorado State University. The center does this by providing drone systems, knowledge, training courses, pilots, and UAS expertise to CSU and the community. The CSU Drone Center maintains a fleet of both multi-rotor and fixed wing sUAS, which are equipped with the latest sensors. The center further has been successful in obtaining several waivers from the FAA for beyond visual line of sight (BVLOS), night flight, and above $122 \mathrm{~m}$ (400 ft AGL) flights in areas in Colorado. The CSU Drone Center has a flight facility at Christman's Airfield, which is the University's sUAS test and training facility.

\section{University of Colorado - Boulder}

As a means of improving precision irrigation (PI), the Lobe Differencing Correlation Radiometer (LDCR) was developed by the University of Colorado at Boulder's (CU) Center for Environmental Technology (CET) and integrated into Black Swift Technology's (BST) sUAS for high resolution soil water mapping. The performance of the sUASbased LDCR has been validated in field experiments in 2015 and 2016 (Dai et al., 2018) during which retrieved soil water maps were produced and favorably compared with in-situ soil water probe data. Compared with the in-situ data, the sUAS-based sensor can provide much more representative space-continuous high-resolution soil water data over broad crop-scale areas at potentially lower cost and greater accuracy. The next critical step toward improving PI will take this new sUAS-based observation method and integrate it into a control loop designed to modulate irrigation valves and sluices to optimize soil water for maximum crop growth. The integrated system would be able to reduce root-zone soil water fluctuations by daily mapping with approximately 10 $\mathrm{m}$ spatial resolution and $2.5 \%$ accuracy.

\section{USDA-ARS-Fort Collins-Colorado}

USDA-ARS Water Management and Systems Research Unit (WMSRU) established a Limited Irrigation Research Farm (LIRF) in Northern Colorado in 2008 and has been conducting research since then on optimizing water management strategies to sustain irrigated agriculture in semi-arid regions with limited water supplies (Comas et al., 2019;
Trout and Bausch, 2017, Zhang et al., 2019). In 2017, the WMSRU developed a sUAS that included multispectral and thermal cameras to collect RS data for irrigation management (Zhang and Yemoto, 2019). The UAS platform is a DJI Spreading Wings S900 hexacopter with 3DR Pixhawk PX4 flight controller/autopilot. The payload for the UAS consists of a FLIR Tau2 LWIR and Tetracam Mini-MCA6 multispectral cameras (see Colorado State University section above for details on the UAS system). A 4.7-ha experimental field was divided into 4 equal sections. In 2017, the western two sections and eastern two sections were used to grow maize and forage sorghum in rotation. Each field section was divided into four replicate blocks, and each block was divided into six $9 \times 43 \mathrm{~m}$ plots containing $12 \mathrm{~N}$-S oriented crop rows $(0.76 \mathrm{~m}$ row spacing) on which six irrigation treatments were randomly assigned. Two variables ( 8 genotypes of maize and 3 irrigation treatments) were tested, with the irrigation treatments receiving $100 \%, 70 \%$, and $40 \%$ of full $\mathrm{ET}_{\mathrm{c}}$. Canopy cover $f_{c}$ and canopy temperature were measured at the center of each plot weekly (near solar noon) by the UAS from a nadir view angle and $15 \mathrm{~m}$ above the ground surface. The missions were programmed with waypoints above the center of each plot, with the UAS orientation locked so the vehicle always faced toward east. At each waypoint the UAS was set to hover pre and post image acquisition to ensure high quality images free of motion blur and orientation bias. Flights were conducted near noon local standard time with the field split into two 10-minute missions. Flight missions were flown at $70 \mathrm{~m}$ AGL; which gave a pixel resolution of $3.79 \mathrm{~cm}$, with an image footprint of $48.6 \mathrm{~m} \times 38.3 \mathrm{~m}$. The missions were programmed to fly north-south with the UAS orientation locked so the vehicle always faced toward the north. Waypoints were programmed to have an image overlap of $90 \%$ and $70 \%$ sidelap with a low flight speed around $1.5 \mathrm{~m} / \mathrm{s}$ to minimize motion blur. The flight pattern over the study site was split into two missions with one transect of overlap between the two missions. Each mission took about 11 min. Images were processed using PixelWrench 2 software (Tetracam Inc., Chatsworth, Calif.), Icaros OneButton Professional 5.1 (Icaros US, Manassas, Va.) and using ESRI ArcGIS 10.4 (ESRI, Redlands, Calif.) depending on the type of images. The UAS based imagery were used in a RS of an $\mathrm{ET}_{\mathrm{a}}$ algorithm. The $\mathrm{ET}_{\mathrm{a}}$ method estimated crop transpiration as $\mathrm{K}_{\mathrm{cb}} \times \mathrm{K}_{\mathrm{s}} \times \mathrm{ET}_{\text {ref. }}$. Where, $\mathrm{K}_{\mathrm{cb}}$ is the basal crop coefficient and $\mathrm{K}_{\mathrm{s}}$ is the stress coefficient. The $\mathrm{K}_{\mathrm{cb}}$ coefficient was $1.10 f_{c}+$ 0.17 (or 1.05 for $f_{c}>0.8$ ), and $\mathrm{K}_{\mathrm{s}}$ was estimated as $1-\mathrm{CWSI}$. Where CWSI is the crop water stress index. CWSI was calculated using canopy temperature derived from UAS thermal data using the method given in Han et al. (2016). The analysis compared crop transpiration derived by UAS images or soil water balance model to on-site sap flow measurements. The results indicated that the UAS-derived crop transpiration estimates were closer to sap flow transpiration measurements than those calculated by soil water balance model with higher adjusted $\mathrm{R}^{2}$ and smaller RMSE. The soil water balance model predicted lower transpiration for stressed plants, but UAS derived transpiration was higher than sap flow measurements for fully irrigated crops. 


\section{NEBRASKA}

Several different groups have been working with UAS systems at the University of Nebraska-Lincoln over the last decade on a variety of applications. For example, the Nimbus Laboratory at UNL (https://nimbus.unl.edu/) has developed UAS applications for water quality sampling (Song et al., 2017) and fire ignition systems (Twidwell et al., 2016). The Nebraska Unmanned Aircraft Innovation, Research and Education (NUAIRE) laboratory (https://nuaire.unl.edu/) has focused more on agricultural applications. A few of the broad-based research programs include deploying UAS to inform adaptive management of variable rate irrigation technology, development of UAS for agricultural biosecurity (Reynolds et al., 2018), and development of autonomous "see and spray" RPAAS technologies (Martin et al., 2019). Over the years, the lab has tested and used several UAS platforms including the fixed-wing Tempest, the Firefly 6 Pro from BirdsEyeView for VTOL capabilities, and more recently the DJI Matrice 600. The lab was able to secure a Part 107 Waiver from the FAA to fly over the UNL ENREC research farm at Mead, NE, up to $244 \mathrm{~m}$ (800 ft) AGL, with most flights conducted at the $244 \mathrm{~m} \mathrm{AGL}$ altitude. This allows the DJI Matrice to cover two quarter section center pivot equipped fields in one flight and battery set. These UAS systems have typically been equipped with the MicaSense RedEdge multispectral camera combined with a thermal infrared imager, and high-resolution optical sensor (Maguire et al., 2017). The lab uses three different thermal infrared cameras namely the FLIR Tau 2 thermal camera with the ThermalCapture device, the FLIR Duo Pro R thermal camera and the TeAx ThermalCapture Fusion Zoom thermal camera. Several research experiments that have been conducted to calibrate both the multispectral and the thermal infrared cameras and results are presented in Maguire (2018a) and Barker et al. (2020). Additional field and laboratory experiments have been conducted to test the factory calibration of the thermal infrared cameras and results are forthcoming. The SETMI hybrid model uses the TSEB formulation for the energy balance estimates of evapotranspiration, requiring accurate surface temperatures, thus the emphasis in calibration of the instruments. UAS informed modeling using SETMI has proven to be useful for producing irrigation prescriptions for Variable Rate Irrigation equipped center pivot systems (Woldt et al., 2018; Maguire et al., 2018b, 2019; Bhatti et al., 2020). Other agricultural applications being worked on using UAS systems are agricultural spray applications using the DJI Agra MG-1 and mapping of wetland areas. Research on agricultural spray operations required the NU-AIRE lab to secure a COA from the FAA.

\section{OKLAHOMA}

A recent survey of agricultural cooperative managers in Oklahoma revealed that most of them had none to very little knowledge about UAS but had above average interest in UAS applications in agriculture. In particular, the average response to interest in UAS applications for assessing crop drought stress was 5.91 on a $0-10$ scale with corresponding values of "not interested at all" to "extremely interested" (Turner, 2016). Interestingly, the surveyed managers were not too concerned about the impacts of regulatory restrictions (altitude limitation and line-of-sight requirement) on the effectiveness of UAS. Besides agricultural managers and producers, urban water/utility managers and golf-course superintendents are also interested in UAS applications to improve irrigation scheduling and water conservation in urban landscape. Another study conducted by Oklahoma State University at two 18-hole championship courses in central Oklahoma indicated that estimating grass water stress index (Taghvaeian et al., 2013) based on the thermal images acquired by a sUAS was effective in mapping water stress across the field and identifying potential issues with the irrigation system (Beyki, 2018). In addition, it was found that the impact of altitude on thermal image accuracy was smallest when images were acquired around solar noon (Beyki, 2018). The sUAS used in this study was selected considering the affordability that is required for most practical applications. This sUAS was an Inspire 1 quadcopter (model T600, DJI Technology Inc., Shenzhen, China) equipped with a thermal camera (Model Zenmuse XT(R), FLIR Systems Inc., Wilsonville, Ore.) that provided images with a resolution of $336 \times 256$ pixels.

\section{TEXAS \\ USDA-ARS-Bushland}

For more than 25 years, precision weighing lysimeters at the USDA-ARS Conservation and Production Research Laboratory (CPRL) have been used to study full- and deficitirrigated crop growth, energy and water balance, $\mathrm{ET}_{\mathrm{c}}, \mathrm{ET}_{\mathrm{a}}$, yield, and water use efficiency for major crops grown in the Southern High Plains (Evett et al., 2016). Through collaboration with Texas A\&M AgriLife Research and Extension and others across the United States, researchers from the CPRL have conducted extensive studies on satellite-based $\mathrm{ET}_{\mathrm{a}} \mathrm{RS}$ to address challenges such as fixed flyover intervals, atmospheric disturbance, and relative low resolution (Gowda et al., 2015). Although UAS-based platforms conceivably avoid many of these issues, research exploring such data for use in irrigation scheduling in Texas is limited, particularly in the intensively irrigated Texas Panhandle region.

In 2018, CPRL researchers began a UAS RS program to explore the usefulness of proximally sensed data for estimating evapotranspiration, determining crop water stress, and irrigation scheduling. Current flight platform inventory includes two professional grade Matrice 600 Pro hexacopters (DJI, Shenzhen, China) equipped with A3 Pro Flight Controller systems, one having high precision navigation and positioning (D-RTK) capability. Maximum payload of 5.5 to $6.0 \mathrm{~kg}$ (depending upon battery capacity) with a maximum lateral speed of $65 \mathrm{~km} / \mathrm{h}$ under no wind conditions. An integrated mount allows for quick interchange of three axis gimbal-equipped cameras, including a DJI Zenmuse X5 16.0 MP RGB camera with a $30 \mathrm{~mm}$ lens, and a DJI Zenmuse XT radiometric thermal camera $(640 \times 512 \mathrm{FPA}, 7.5$ to $13.5 \mu \mathrm{m})$. Positional data for images acquired via cameras using the integrated gimbal mounting system are obtained from the A3 flight controller. An offset fixed-mount RedEdge-MX ${ }^{\mathrm{TM}}$ (Micasense Inc., Seattle, Wash.) camera allows for concurrent image capture with either of the Zenmuse cameras. The RedEdge camera captures blue, 
green, red, red edge, near infrared (NIR) bands $(1280 \times 960)$ and uses its own GPS receiver. Maximum flight time varies depending upon payload, wind resistance, and temperature. The Matrice 600 Pro requires six intelligent DJI batteries. Standard TB47S (4500 $\mathrm{mAh})$ and long run TB48S $(5700 \mathrm{mAh})$ batteries are available. Flights using the Matrice 600 Pro equipped with both the RedEdge MX and a gimbal mounted camera are typically limited to $25 \mathrm{~min}$. However, test flights have reached nearly 30 min under low wind conditions, using the TB48S batteries. Other testing activities have demonstrated that the Matrice 600 is an exceptionally reliable and stable flight platform in wind conditions exceeding the $8.3 \mathrm{~km} / \mathrm{h}$ rating, yielding high quality imagery acceptable for processing. Other test flights have been designed to evaluate the interactions of flight altitude and speed on image resolution and image stitching and post-processing operations.

A primary research goal is to compare $\mathrm{ET}_{\mathrm{a}}$ estimates from same-day satellite and UAS-acquired imagery using surface energy balance $\mathrm{ET}_{\mathrm{a}}$ models. Although similar efforts have been performed, imagery of the CPRL weighing lysimeter fields allows for comparison of both proximal and satellitederived $\mathrm{ET}_{\mathrm{a}}$ estimates with measured $\mathrm{ET}_{\mathrm{a}}$ values. A second research goal is to explore the usefulness of UAS-based crop canopy temperature data for use in automated center pivot irrigation control systems. Currently, infrared thermometer (IRT) measurements of crop canopy temperature are used with soil water sensor data to compute a crop water stress index to schedule irrigation using an Irrigation Scheduling Supervisory Control and Data Acquisition System (ISSCADAS) (Andrade et al., 2015). However, canopy temperature measurements are limited by center pivot travel speed, resulting in an intrinsic lag condition between time of measurement and irrigation application. In contrast, measurements of crop canopy temperature may be obtained in minutes via UAS-platform, providing timely temperature data for integration into irrigation prescription maps.

\section{UTAH \\ Utah State University - AggieAir UA V Research Program}

Utah State University has been investing in the implementation or small aerial technology for mapping and data collection for the last 14 years. The research and development of UAV technology and applications is grouped in the AggieAir UAV Research Program (www.uwrl.usu.edu/aggieair) towards an understanding and monitoring of water and energy fluxes in natural and agricultural environments as well as atmospheric, wildlife, and civil engineering applications. AggieAir development for agricultural science is defined with past historical benchmarks such as development of radio-controlled delta wing with RGB and NIR cameras; integration of thermal camera and UAV flights at high elevations (300 to $400 \mathrm{~m} \mathrm{AGL);} \mathrm{UAV} \mathrm{endurance} \mathrm{flights} \mathrm{over}$ 259 ha (one square mile) coverage; applications of UAVs for evapotranspiration, soil water, chlorophyll content, and Landsat comparison; and partnership with USDA-ARS to conduct trial flights over vineyards in California for evapotranspiration estimation. Currently the AggieAir UAV Program is developing large-scale UAV to respond to the
American agricultural scale with 3-h flights, $1 \mathrm{~km}$ AGL, with a targeted acreage of $155.4 \mathrm{~km}^{2}\left(60 \mathrm{mi}^{2}\right)$.

Regarding applications of UAV in agriculture, significant advances were made. A selected list of efforts are mentioned here: a) Landsat-UAV data harmonization (Aboutalebi et al., 2018b) to evaluate potential biases on UAV information and direct comparison to Landsat satellite products; b) Atmospheric impact on UAS thermal information (Torres-Rua, 2017), to address atmospheric conditions with the advent of stronger UAVs (e.g. BVLOS); c) UAV optical and thermal spectral and spatial uncertainty impact (McKee et al., 2018) to evaluate potential issues caused by spectral and location biases towards estimation of evapotranspiration; d) Shadow impact on UAS optical and thermal products (Aboutalebi et al., 2019a), to evaluate shadow effect in orchards and vineyards on vegetation indices, to biomass and surface energy balance; e) Estimation of energy balance fluxes for vineyards crops using UAS (Nieto et al., 2015; Nieto et al., 2019), an adaptation of the TSEB approach to the uniqueness of vine orchards; f) Soil water estimation using UAS (Hassan-Esfahani et al., 2015), application of machine learning approaches for soil water content; g)Yield and biomass estimation using UAS (Aboutalebi et al., 2018a); h) use of point cloud in estimation of evapotranspiration (Aboutalebi et al., 2020); and i) Pixel size impact on the estimation of ET using UAV (Nassar et al., 2020), to assess the changes in ET estimation accuracy for energy balance and ET with fine and coarser pixels. These studies, along with other researchers (Kustas et al., 2018), provide the necessary support for additional UAV development such as use of beyond line of sight UAVs and drone swarm, real-time agricultural applications, and integration of UAV and satellite information for agriculture.

\section{ARKANSAS}

In the Delta region of eastern Arkansas, West and Kovacs (2017) compared the cost effectiveness of utilizing soil water sensors and UAS to implement precision variable-rate irrigation. The net return per unit volume of groundwater conserved by utilizing soil water sensors was slightly larger compared to the UAS at $\$ 7.37$ versus $\$ 6.23$ per $1,000 \mathrm{~m}^{3}$ of groundwater ( $\$ 9.09$ versus $\$ 7.69$ per acre-ft), respectively. The soil water sensing; however, is more expensive per unit area, and thus UAS was found to be more cost-effective.

\section{DISCUSSION}

\section{Advances}

Current advances in UAS technology (platforms, sensors, software) for irrigation water management are promising. The technology has advanced to a degree that mapping $\mathrm{K}_{\mathrm{ca}}$, $\mathrm{ET}_{\mathrm{a}}$, and soil water status, at very high spatial resolutions, are possible. However, acquiring such imagery frequently (several times per week) and over large areas remains a challenge.

Given current and expected future regulations, it is expected that UAS can have a large and growing impact on commercial agricultural activities. Synergistics efforts with satellite products (such as Landsat $\mathrm{ET}_{\mathrm{a}}$ ) implies additional 
research to achieve equivalent products such as: $\mathrm{ET}_{\mathrm{a}}$ mapping, crop water stress estimation, and biomass estimation. For instance, regarding $\mathrm{ET}_{\mathrm{a}}$ mapping, Landsat products at $30 \mathrm{~m}$ spatial resolution and 8-day frequency has reached a significant maturity that operational platforms are in development. While Landsat $\mathrm{ET}_{\mathrm{a}}$ can be used for field scale decision-making activities and be adequate for full cover crops (commodity crops), UAS can play a significant role in monitoring crop and specialty crops (vineyards, orchards) where Landsat resolution does not provide clear information on crop status, especially early in the season. Regarding crop water stress estimation, monitoring temperature or stress conditions is critically important in certain crops such as potatoes, orchards, and vineyards. Landsat derived products (imagery pixels) can be "refined" regarding only crop (or only soil for potatoes) temperature conditions with information from UAS thermal imagery. In terms of biomass estimation, until now neither Landsat, nor any other satellite, have been able to provide an estimation of biomass from space, although the GEDI satellite is expected to provide continuous information of crop vertical development at coarse resolution. UAS digital elevation models from photogrammetry or LIDAR sensors can complement and refine biomass satellite products' estimations (Poley and McDermid, 2020).

\section{LIMITATIONS \\ UAS Platforms}

Fixed Wing: Fixed wing platforms offer greater flexibility in the ability to fly small as well as larger areas in a single flight. This is because of their larger range of their fuel (or battery power) reserves due to relying on a traditional fixed airfoil. Fixed airfoils are by nature more fuel efficient in lift than a rotary wing. The tradeoff is the degree of skill required to operate these platforms. Advances in technology have decreased the training time of pilots as more autonomous fixed wing UAS have been developed. However, the skill set required is still quite high when compared to a multirotor platform. Most fixed wing platforms also suffer from needing a large area to land. This can present logistical challenges to finding a suitable landing location near flight areas. Advances in this area are occurring to reduce the space needed. Some of these advances are deep stall, air bag, parachute, and nets to catch the drone. Most fixed wings UAS still rely on traditional belly landing or landing gear. One of the greatest drawbacks to fixed wing UAS is the required minimum forward flight speed. Most have a minimum stall speed between 10 to $20 \mathrm{~m} / \mathrm{s}$. This can present a challenge to map areas at low altitudes. Often sensor/camera reset times are above $1 \mathrm{~s}$. When proper overlap of images is required, the sensor cannot reset fast enough to capture the required images due to the speed of the fixed wing UAS.

Multi-Rotor: Multi-rotor UAS offer the ability to carry a variety of sensors and their payload configurations can be customizable depending on the system. Multi-rotor UAS greatest quality is the ability to hover, take off vertically, and control the speed of the mapping mission. The skill set to learn to fly and operate the multi-rotor is generally lower and not as complex as fixed wing UAS. Multi-rotor UAS can be programmed to complete mapping missions with little or no pilot input during the mission. The greatest drawback of multi-rotor systems is the short flight time and inability to efficiently map large areas. With realistic mission flight times of 10-30 min it means only small areas can be covered at one time.

Hybrid Systems: Hybrid systems attempt to blend the vertical takeoff of a rotary wing UAS with the efficacy of a fixed wing. They excel in offering the ability to take off and land in smaller areas, and generally have longer flight times than rotary wing UAS. Their main drawback is they generally have very small payload capabilities. The skill set to operate them is moderate but not as complex as pure fixed wing platforms.

\section{UAS Sensors}

Generally, UAS flight speed is limited by the reset time of the camera. With UAS flying at lower altitudes or higher speeds the sensors cannot reset in time to achieve proper overlapping for mapping. As weight is always a concern with UAS to keep within maximum payload and to provide long flight times, the size and configuration of sensors can be limited. Sensors have advanced to become lighter and smaller and designed specifically for UAS applications. However, this has resulted in some sensors that may not be as accurate as terrestrial based sensors. An example is using uncooled microbolometer sensors in thermal cameras. One challenge of using these uncooled sensors is the need to allow them to heat up or cool down to their standard operating temperature (stabilize) prior to UAS flight and mapping. This often requires an on the ground "warm up" period of 20-30 min for the sensor, prior to flight. In order to prevent premature draw from the aircraft batteries it is recommended to power the thermal sensor with an auxiliary lithium polymer battery.

UAS Software: Software for mapping of agriculture has advanced greatly in the recent years, specifically in the area of RGB and multispectral orthro-mosaics. It is a challenge to consistently produce high quality thermal ortho-mosaics. The software programs will at times produce accurate thermal ortho-mosaics, and in other data sets collected in the same manner under the same conditions not be able to properly stitch the images together.

Other Limiting Factors: One of the limitations is the altitude restriction of $122 \mathrm{~m} \mathrm{AGL}$. This limitation introduces at least two challenges to continued advancement of the technology. The first challenge relates to "aerial coverage per flight." Given the somewhat limited flight duration of UAS, an increase in the maximum altitude to perhaps $244 \mathrm{~m} \mathrm{AGL}$ would provide opportunity for increasing the aerial coverage per flight by four times. At this altitude, coverage of typical size for a center pivot system ( $65 \mathrm{ha}$ ) becomes feasible with current UAS. The second challenge is image processing. Flight over agricultural crops at $122 \mathrm{~m}$ provides imagery that can be difficult to process using currently available stitching software. Increasing altitude, while reducing the resolution, provides a greater variety of patterns, and thus opportunity for stitching software to successfully process the data into a mosaic. Another challenge in current Part 107 regulations that requires to maintain the UAS within line of sight 
(VLOS). Regulations that permit flight of UAS "beyond visual line of sight" (BVLOS) would be beneficial for the agricultural irrigation industry. Agricultural applications, by their nature, imply management of large expanses of land with low population densities. In a manner similar to an increase in the maximum ceiling for UAS flights, relieving the requirement to keep the UAS within line of sight for agricultural flight operations, has the potential to increase adoption of UAS for irrigation management. Research on battery design, hydrogen fuel cells, and other emerging technologies are likely to increase the flight duration of UAS, and an associated legal framework supporting long duration flights, that occur BVLOS would be beneficial to irrigated agriculture.

Use of UAS is still expensive, compared to some satellites products that are freely accessible, UAS require investment in equipment, personnel (pilots, image processing specialist), ground control points, access to internet, powerful computers, large storage capacity (digital memory), and ground information for validation of results $\left(\mathrm{ET}_{\mathrm{a}}\right.$, biomass, soil water, chlorophyll, nitrogen, etc.). Large high-value agricultural companies with GIS teams/departments have been the early adopters/users to be able to test and incorporate UAS technology in an operational manner.

Lack of sensor standards limits replicability of studies and usability of algorithms: As the UAS technology in the market continues evolving, past research efforts and algorithms must be revisited to assess the compatibility with newer / updated sensors.

The current UAS technology does not deliver irrigation prescription maps in timely manner (long image processing time, concurrent on-site data acquisition, etc.)

\section{INNOVATION NEEDS}

a. Understanding of American agriculture scale and need for further UAS technology and regulation development: Current UAS aircrafts and sensor technology are mostly used by agricultural technology enthusiasts with limited penetration or use in most agricultural activities. This is because of multiple reasons such as need for complex algorithms and ground sensors for crop water estimation, limited area coverage by regulation ( $\sim 40.5$ ha at $122 \mathrm{~m} \mathrm{AGL}$ or 100 acre at $400 \mathrm{ft}$ AGL), lack of affordable sub meter accuracy GPS/IMU UAS technology, integration of thermal sensing in UAS sensors, among others.

b. Standards for sensing, processing, and products: In the UAV sensors market, there are not two equivalent sensors providers and none of the available sensors is comparable to scientific sensors as those used by Landsat. Similarly, UAS image processing software are of the "black box" type, with limited understanding of the transformation to the information carried by the pixels. In commercial UAV products, only basic information such as NDVI and other vegetation indices, and plant counting are produced. However, with a need to make reliable advanced estimations of evapotranspiration, soil water, crop biomass, crop water stress and other research products the UAS technology (e.g., data processing, ET algorithms) has to further be developed for a general application/implementation adoption.

c. BVLOS UAVs in Agriculture: American agriculture is of large scale, and current UAS technology does not respond to it. BVLOS UAS advances are expected to make UAS operations "cost-effective" so commercial applications (as a service or part of producer sets of tools) can appear, potentially replacing or working synergistically with manned aircraft operations. (McKee et al., 2019)

d. Image Processing and GPS accuracy: Image processing is done after flight in local or cloud services with significant computational time, which is expected to grow exponentially with BVLOS UAS. Alternatives to image processing that replace the "structure from motion" are appearing, with faster times and similar quality as current image processing solutions. Structure from motion is defined as "a photogrammetric range imaging technique for estimating three-dimensional structures from two-dimensional image sequences that may be coupled with local motion signals. It is studied in the fields of computer vision and visual perception. Current Onboard GPS accuracy is limited $( \pm 3 \mathrm{~m})$ and affect significantly UAS products for row crops. While future technologies such as 5G, newer GPS satellites, and satellite internet are promising, their evolution and cost will define their adaption to agricultural activities.

Thus, desired advances may include:

a. Development of a true "one-button" system to be operated by relatively unskilled people. A UAS/Sensor/Software system which would, once programmed, routinely fly an agricultural site, download the data, process the data, and provide analysis and interpreted results to the farmer autonomously.

b. Sensors which can internally reset faster to allow for greater mapping speeds of the UAS at higher imagery acquisition overlap percentages.

c. Lightweight and compact thermal sensor with a cooledsensor system to acquire accurate thermal imagery.

d. Development of fuel systems which would allow for longer flight times on multi-rotor aircraft. Some of these systems are currently being developed but are bulky and greatly reduce payload capacity. Some of these include hybrid electric systems and hydrogen fuel cells.

e. Integrated multispectral, thermal, RGB payload packaged. Currently the only way to possess such a system is to custom build and integrate it into a UAS. This requires a high degree of knowledge to both build and operate.

f. Faster processing times and automation of ortho-mosaicking software. Current software often takes hours or days to process data sets depending on the size. Innovation for less required user input.

g. Further development of thermal ortho-mosaic programs or capabilities.

h. Faster and less complicated FAA authorization process for flights occurring in uncontrolled airspace above 
$122 \mathrm{~m}$ AGL. This process is currently very complicated and often takes so long it makes research flights at this level impossible to achieve in the necessary time frame.

i. Development of a system which would allow for greater integration of UAS into the national airspace system. Currently all UAS flights are regulated to uncontrolled airspace or "Class G" below $122 \mathrm{~m} \mathrm{AGL,} \mathrm{without} \mathrm{prior}$ authorization. Implementing a system which would allow UAS to be operated at higher altitudes and in certain levels of controlled airspace, while tracking, identifying, and avoiding manned aviation is key. This would need to be accomplished through technology, regulations, and aviation practices.

j. Integration of calibrated sUAS-based surface reflectance and temperature imagery/mosaics with groundbased (field) environmental sensor (e.g., weather stations, soil water) data and robust algorithms for routine mapping of crop bio-physical characteristics, crop water use/stress, soil water depletion, and forecast of water needs and crop yield. The integration should be performed on a timely manner (on-line/cloud preferable). Zhang et al. (2017) and Chávez et al. (2010) provide details regarding remote sensing and wireless sensor data integration for precision crop/water management.

\section{PATH FORWARD}

Irrigation is critical for worldwide food production. At the same time, there is increasing pressure on our water resources, which prompts us to manage our water more precisely. In the U.S. Great Plains, conversion to center pivot irrigation along with other advancements in technology and communication has already improved the application efficiency of irrigation significantly while maintaining or increasing yields. The next step forward for advancing irrigation management, especially in the sub-humid eastern portion of the Great Plains, is increasing the adoption rates of scientific irrigation scheduling (SIS). The primary benefit of SIS is reduced pumping for irrigation while sustaining yield, although in some cases it can also lead to increases in yield.

While SIS has been promoted for decades, adoption rates have remained relatively low. Primary barriers to adoption include the labor required for SIS and the lack of a significant economic incentive. Another barrier is that, while several methods for SIS have been proposed, each method has uncertainty associated with it and is currently deemed inadequate as a complete solution for SIS. While precision agriculture and UAS result in more data availability, producers often feel overwhelmed with data and struggle to convert data into actionable decisions.

Adoption rates of SIS for center pivot irrigation would likely be much higher if SIS was automated and reliable at large spatial scales. Irrigation automation would use SIS to reduce pumping for irrigation without increasing labor requirements. In order to be automated, irrigation systems will need to be sensor-driven. In order to be reliable, irrigation automation will need to incorporate multiple types of sensors (both proximal and RS) and multiple approaches to SIS, which will reduce the uncertainty associated with the deci- sion of when and how much to irrigate. UAS provides another data layer at a resolution previously not feasible. Other related trends in agriculture include decreasing cost of sensors, decreasing cost of communicating with the cloud, the Internet of Things (IoT), increasing lead time in accurate weather forecasting, and decision support systems on smart phones. Yet another trend is merging RS data from multiple sensors (ground, air, and space borne) that present different spatial and temporal resolutions to enhance the application of SIS. These technologies make irrigation automation more possible and have the potential to remove barriers (e.g., time and expense) to adoption. Data science will be a key component for processing large volumes of data from multiple data sources (Mendes et al., 2019). As SIS becomes more complex, it is becoming more important for industry and public institutions to partner together to develop innovative solutions that get transferred to producers and make an impact.

\section{ACKNOWLEDGEMENTS}

Colorado State University (CSU) UAS operation and research has been funded by: CSU Civil and Environmental Engineering Department (Borland Hydrology), Colorado Water Conservation Board (CWCB), Northern Colorado Water Conservancy District (CNWCD), CSU Drone Center, CSU Irrigation Innovation Consortium (through the Foundation for Food and Agriculture Research, FFAR), and USDA NIFA award number 2016-68007-25066, "Sustaining agriculture through adaptive management to preserve the Ogallala aquifer under a changing climate." At Colorado State University, the contribution provided by Mr. Ashish Masih is greatly appreciated. University of Nebraska research was funded in part by USDA-NIFA Foundational program (Award\# 2017-67021-26249) and the Daugherty Water for Food Global Institute, University of Nebraska. The AggieAir UAV Research Program is funded by the Utah Water Research Laboratory at Utah State University and NASA Grant NNX17AF51G and USDA ARS multiple grants. Our gratitude is extended to anonymous reviewers and Editors (Freddie Lamm and Todd Trooien), from ASABE, Natural Resources \& Environmental Systems, Journal Applied Engineering in Agriculture, who provided valuable criticism to improve the quality of this article.

\section{REFERENCES}

Aboutalebi, M., Torres-Rua, A. F., \& Allen, N. (2018a). Multispectral remote sensing for yield estimation using highresolution imagery from an unmanned aerial vehicle. Proc. SPIE Commercial + Scientific Sensing and Imaging. 10664. SPIE. https://doi.org/10.1117/12.2305888

Aboutalebi, M., Torres-Rua, A. F., Kustas, W. P., Nieto, H., Coopmans, C., \& McKee, M. (2019a). Assessment of different methods for shadow detection in high-resolution optical imagery and evaluation of shadow impact on calculation of NDVI, and evapotranspiration. Irrig. Sci., 37(3), 407-429.

https://doi.org/10.1007/s00271-018-0613-9 
Aboutalebi, M., Torres-Rua, A. F., McKee, M., Kustas, W. P., Nieto, H., Alsina, M. M.,... Dokoozlian, N. (2020). Incorporation of unmanned aerial vehicle (UAV) point cloud products into remote sensing evapotranspiration models. Remote Sensing, 12(1), 50. Retrieved from https://www.mdpi.com/20724292/12/1/50

Aboutalebi, M., Torres-Rua, A. F., McKee, M., Nieto, H., Kustas, W. P., Prueger, J. H.,... Coopmans, C. (2018b). Assessment of Landsat harmonized sUAS reflectance products using point spread function (PSF) on vegetation indices (VIs) and evapotranspiration (ET) using the two-source energy balance (TSEB) model. Proc. AGU Fall Meeting. (pp. H33I-2193).

Aboutalebi, M., Torres-Rua, A. F., McKee, M., Nieto, H., Kustas, W., \& Coopmans, C. (2019b). The impact of shadows on partitioning of radiometric temperature to canopy and soil temperature based on the contextual two-source energy balance model (TSEB-2T). Proc. SPIE Defense + Commercial Sensing. 11008. SPIE. https://doi.org/10.1117/12.2519685

Allen, R. G., Tasumi, M., \& Trezza, R. (2007). Satellite-based energy balance for mapping evapotranspiration with internalized calibration (METRIC)-Model. J. Irrig. Drain. Eng., 133(4), 380394. https://doi.org/10.1061/(ASCE)07339437(2007)133:4(395)

Andrade, M. A., O’Shaughnessy, S. A., \& Evett, S. R. (2015). Advances in irrigation management tools: The development of ARSmartPivot. Proc. ASABE / IA Irrigation Symp.: Emerging Technologies for Sustainable Irrigation - A Tribute to the Career of Terry Howell, Sr. (pp. 1-12). St. Joseph, MI: ASABE. https://doi.org/10.13031/irrig.20152170793

Avtar, R., \& Watanabe, T. (2020). Unmanned aerial vehicle: Applications in agriculture and environment. Cham: Springer Nature Switzerland. https://doi.org/10.1007/978-3-030-27157-2

Barker, J. B., Bhatti, S., Heeren, D. M., Neale, C. M., \& Rudnick, D. R. (2019). Variable rate irrigation of maize and soybean in West-Central Nebraska under full and deficit irrigation. Frontiers Big Data, 2(34). https://doi.org/10.3389/fdata.2019.00034

Barker, J. B., Heeren, D. M., Neale, C. M., \& Rudnick, D. R. (2018b). Evaluation of variable rate irrigation using a remotesensing-based model. Agric. Water Manag., 203, 63-74. https://doi.org/10.1016/j.agwat.2018.02.022

Barker, J. B., Neale, C. M., Heeren, D. M., \& Suyker, A. E. (2018a). Evaluation of a hybrid reflectance-based crop coefficient and energy balance evapotranspiration model for irrigation management. Trans. ASABE, 61(2), 533-548. https://doi.org/10.13031/trans.12311

Barker, J. B., Woldt, W. E., Wardlow, B. D., Neale, C. M., Maguire, M. S., Leavitt, B. C., \& Heeren, D. M. (2020). Calibration of a common shortwave multispectral camera system for quantitative agricultural applications. Precis. Agric. https://doi.org/10.1007/s11119-019-09701-6

Beyki, S. (2018). Mapping water stress on bermudagrass golf course fairways using thermal remote sensing. MS thesis. Stillwater: Oklahoma State University, Department of Horticulture and Landscape Architecture.

Bhatti, S., Heeren, D. M., Barker, J. B., Neale, C. M., Woldt, W. E., Maguire, M. S., \& Rudnick, D. R. (2020). Site-specific irrigation management in a sub-humid climate using a spatial evapotranspiration model with satellite and airborne imagery. Agric. Water Manag., 230, 105950. https://doi.org/10.1016/j.agwat.2019.105950

Chavez, J. L. (2017). Fixed-wing unmanned aerial systems for improved irrigation management. Proc. 29th Annual Central Plains Irrigation Conf. (CPIC). Retrieved from https://www.kstate.edu/irrigate/oow/cpic17.html
Chavez, J. L., Gowda, P. H., Howell, T. A., Garcia, L. A., Copeland, K. S., \& Neale, C. M. (2012). ET mapping with highresolution airborne remote sensing data in an advective semiarid environment. J. Irrig. Drain. Eng., 138(5), 416-423. https://doi.org/10.1061/(ASCE)IR.1943-4774.0000417

Chavez, J. L., Pierce, F. J., Elliott, F. J. \& Evans, R. G. (2010). A remote irrigation monitoring and control system (RIMCS) for continuous move systems. Part A: Description and development. Precis. Agric., 11, 1-10

Chavez, J., Zhang, H., Capurro, M. C., Masih, A., \& Altenhofen, J. (2018). Evaluation of multispectral unmanned aerial systems for irrigation management. Proc. SPIE Commercial + Scientific Sensing and Imaging. 10664. SPIE. https://doi.org/10.1117/12.2305076

Comas, L. H., Trout, T. J., DeJonge, K. C., Zhang, H., \& Gleason, S. M. (2019). Water productivity under strategic growth stagebased deficit irrigation in maize. Agric. Water Manag., 212, 433440. https://doi.org/10.1016/j.agwat.2018.07.015

Dai, E., Venkitasubramony, A., Gasiewski, A., Stachura, M., \& Elston, J. (2018). High spatial soil moisture mapping using small unmanned aerial system. Proc. IEEE Int. Geoscience and Remote Sensing Symp., (pp. 6496-6499). https://doi.org/10.1109/IGARSS.2018.8518730

Dhungel, R., Aiken, R., Colaizzi, P. D., Lin, X., O’Brien, D., Baumhardt, R. L.,... Marek, G. W. (2019). Evaluation of uncalibrated energy balance model (BAITSSS) for estimating evapotranspiration in a semiarid, advective climate. Hydrol. Process., 33(15), 2110-2130. https://doi.org/10.1002/hyp.13458

Dhungel, R., Aiken, R., Lin, X., Kenyon, S., Colaizzi, P. D., Luhman, R.,... Brauer, D. K. (2020). Restricted water allocations: Landscape-scale energy balance simulations and adjustments in agricultural water applications. Agric. Water Manag., 227, 105854. https://doi.org/10.1016/j.agwat.2019.105854

Evett, S. R., Howell Sr., T. A., Schneider, A. D., Copeland, K. S., Dusek, D. A., Brauer, D. K.,... Gowda, P. H. (2016). The Bushland weighing lysimeters: A quarter century of crop ET investigations to advance sustainable irrigation. Trans. ASABE, 59(1), 163-179. https://doi.org/10.13031/trans.59.11159

FAA. (2020). Airspace designation. FAA. Retrieved from https://www.faa.gov/regulations_policies/handbooks_manuals/a viation/phak/media/17_phak_ch15.pdf

FAA, NPRM. (2019). FAA, NPRM. Retrieved from https://www.federalregister.gov/documents/2019/12/31/201928100/remote-identification-of-unmanned-aircraft-systems

Geli, H. M., \& Neale, C. M. (2012). Spatial evapotranspiration modelling interface (SETMI). Proc. Remote Sensing and Hydrology, (pp. 171-174).

Gonzalez Toro, F., \& Tsourdos, A. (2018). UAV or drones for remote sensing applications (Vol. 1). Basel, Switzerland: MDPI.

Gowda, P. H., Chavez, J. L., Colaizzi, P. D., Evett, S. R., Howell, T. A., \& Tolk, J. A. (2008). ET mapping for agricultural water management: Present status and challenges. Irrig. Sci., 26(3), 223-237. https://doi.org/10.1007/s00271-007-0088-6

Gowda, P. H., Howell Jr., T. A., Chavez, J. L., Paul, G., Moorhead, J. E., Holman, D.,... Brauer, D. K. (2015). A decade of remote sensing and evapotranspiration research at USDA-ARS Conservation and Production Research Laboratory. Proc. ASABE / IA Irrigation Symp.: Emerging Technologies for Sustainable Irrigation - A Tribute to the Career of Terry Howell, Sr. (pp. 1-14). St. Joseph, MI: ASABE.

https://doi.org/10.13031/irrig.20152143458

Han, M., Zhang, H., Chavez, J. L., Ma, L., Trout, T. J., \& DeJonge, K. C. (2018). Improved soil water deficit estimation through the integration of canopy temperature measurements into a soil water balance model. Irrig. Sci., 36(3), 187-201. https://doi.org/ 
Han, M., Zhang, H., DeJonge, K. C., Comas, L. H., \& Trout, T. J. (2016). Estimating maize water stress by standard deviation of canopy temperature in thermal imagery. Agric. Water Manag., 177, 400-409. https://doi.org/10.1016/j.agwat.2016.08.031

Hassan-Esfahani, L., Torres-Rua, A., Jensen, A., \& McKee, M. (2015). Assessment of surface soil moisture using highresolution multi-spectral imagery and artificial neural networks. Remote Sensing, 7(3), 2627-2646. https://doi.org/10.3390/rs70302627

Hathaway, J. C. (2016). Integration of an unmanned aircraft system and ground-based remote sensing to estimate spatially distributed crop evapotranspiration and soil water deficit throughout the vegetation soil root zone. MS thesis.. Fort Collins: Colorado State University, Civil and Environmental Engineering Department. Retrieved from http://hdl.handle.net/10217/173478

Kustas, W., Anderson, M. C., Alfieri, J., Knipper, K., Torres-Rua, A., Parry, C. K.,... Hain, C. (2018). The grape remote sensing atmospheric profile and evapotranspiration experiment. Bull. American Meteorol. Soc., 99(9), 1791-1812. https://doi.org/10.1175/BAMS-D-16-0244.1

Maguire, M. (2018). An evaluation of unmanned aerial system multispectral and thermal infrared data as information for agricultural crop and irrigation management. MS thesis. University of Nebraska-Lincoln, Biological Systems Engineering Department. Retrieved from http://digitalcommons.unl.edu/biosysengdiss/82/

Maguire, M. S., Woldt, W. E., Frew, E. E., Smith, J., \& Elston, J. (2017). Thermal infrared and multi-spectral dual sensor integration for unmanned aircraft systems. ASABE Paper No. 1701455. St. Joseph, MI: ASABE. https://doi.org/10.13031/aim.201701455

Maguire, M., Barker, J., Neale, C., Woldt, W., \& Suyker, A. (2018). Modeling evapotranspiration using multispectral and thermal infrared imagery acquired with a low altitude unmanned aerial system. Proc. Annual International Meeting of ASABE. ASABE.

Maguire, M., Neale, C., \& Woldt, W. (2019). Modeling evapotranspiration using multispectral and thermal infrared imagery acquired with a low altitude unmanned aerial system. Proc. USCID 12th Int. Conf. on Irrigation and Drainage. U.S. Commission on Irrigation and Drainage.

Martin, D. E., Woldt, W. E., \& Latheef, M. A. (2019). Effect of application height and ground speed on spray pattern and droplet spectra from remotely piloted aerial application systems. Drones, 3(4), 83. https://doi.org/10.3390/drones3040083

McKee, M., Nassar, A., Torres-Rua, A., Aboutalebi, M., \& Kustas, W. (2018). Implications of sensor inconsistencies and remote sensing error in the use of small unmanned aerial systems for generation of information products for agricultural management. Proc. SPIE Commercial + Scientific Sensing and Imaging. 10664. SPIE. https://doi.org/10.1117/12.2305826

McKee, M., Torres-Rua, A., Aboutalebi, M., Nassar, A., Coopmans, C., Kustas, W.,... Alsina, M. (2019). Challenges that beyond-visual-line-of-sight technology will create for UASbased remote sensing in agriculture. Proc. SPIE Defense + Commercial Sensing. 11008. SPIE. https://doi.org/10.1117/12.2520248

Mendes, W. R., Araujo, F. M., Dutta, R., \& Heeren, D. M. (2019). Fuzzy control system for variable rate irrigation using remote sensing. Expert Syst. Appl., 124, 13-24. https://doi.org/10.1016/j.eswa.2019.01.043
Morande, J. A., Trezza, R., Anderson, A., Tha, K., Paw, Y. J., Chen, Y., \& Viers, J. 2. (2020). Medellin-Azuara, J. Appendix K. Evapotranspiration estimation from unmanned aerial vehicles. UC Water Secur. Sustain. Res. Initiat. Interim Report. Retrieved from https://watershed.ucdavis.edu/files/Appendix\%20K_ETUAV_Delta\%20Report_1.pdf

Nassar, A., Torres-Rua, A., Kustas, W., Nieto, H., McKee, M., Hipps, L., ... \& McKee, L. (2020). Influence of model grid size on the estimation of surface fluxes using the two source energy balance model and suas imagery in vineyards. Remote Sensing, 12(3), 342.

Neale, C. M. U., Bausch, W. C., \& Heermann, D. F. (1989). Development of reflectance-based crop coefficients for corn. Trans. ASAE, 32(6), 1891-1900. https://doi.org/10.13031/2013.31240

Neale, C. M. U., Geli, H. M., Kustas, W. P., Alfieri, J. G., Gowda, P. H., Evett, S. R.,... Howell, T. A. (2012). Soil water content estimation using a remote sensing based hybrid evapotranspiration modeling approach. Adv. Water Resour., 50, 152-161. https://doi.org/10.1016/j.advwatres.2012.10.008

Nieto, H., Kustas, W. P., Torres-Rua, A., Alfieri, J. G., Gao, F., Anderson, M. C.,... McKee, L. G. (2019). Evaluation of TSEB turbulent fluxes using different methods for the retrieval of soil and canopy component temperatures from UAV thermal and multispectral imagery. Irrig. Sci., 37(3), 389-406. https://doi.org/10.1007/s00271-018-0585-9

Nieto Solana, H., Kustas, W. P., Torres-Rua, A. F., ELarab, M., Song, L., Alfieri, J. G., ... \& Jensen, A. (2015, December). Advances in the Two Source Energy Balance (TSEB) model using very high resolution remote sensing data in vineyards. In AGU Fall Meeting Abstracts.

Niu, H., Zhao, T., Wang, D., \& Chen, Y. (2019). A UAV resolution and waveband aware path planning for onion irrigation treatments inference. Proc. Int. Conf. on Unmanned Aircraft Systems (ICUAS), (pp. 808-812). https://doi.org/10.1109/ICUAS.2019.8798188

Poley, L. G., \& McDermid, G. J. (2020). A systematic review of the factors influencing the estimation of vegetation aboveground biomass using unmanned aerial systems. Remote Sensing, 12(7), 1052. https://doi.org/10.3390/rs12071052

Reynolds, D., Woldt, W., \& Oetjen, M. (2018). The Big Red Biosecurity Program for poultry develops drone technology for biosurveillance. (Abstract number: 1794 ed.). Proc. Conf. American Veterinary Medical Association (AVMA).

Sankaran, S., Khot, L. R., Espinoza, C. Z., Jarolmasjed, S., Sathuvalli, V. R., Vandemark, G. J.,... Pavek, M. J. (2015). Lowaltitude, high-resolution aerial imaging systems for row and field crop phenotyping: A review. Eur. J. Agron., 70, 112-123. https://doi.org/10.1016/j.eja.2015.07.004

Seifert, E., Seifert, S., Vogt, H., Drew, D., van Aardt, J., Kunneke, A., \& Seifert, T. (2019). Influence of drone altitude, image overlap, and optical sensor resolution on multi-view reconstruction of forest images. Remote Sensing, 11(10), 1252. https://doi.org/10.3390/rs11101252

Song, K., Brewer, A., Ahmadian, S., Shankar, A., Detweiler, C., \& Burgin, A. J. (2017). Using unmanned aerial vehicles to sample aquatic ecosystems. Limnol. Oceanogr. Methods, 15(12), 10211030. https://doi.org/10.1002/lom3.10222

Taghvaeian, S., Chavez, J. L., Hattendorf, M. J., \& Crookston, M. A. (2013). Optical and thermal remote sensing of turfgrass quality, water stress, and water use under different soil and irrigation treatments. Remote Sensing, 5(5), 2327-2347. https://doi.org/10.3390/rs5052327 
Torres-Rua, A. (2017). Vicarious calibration of sUAS microbolometer temperature imagery for estimation of radiometric land surface temperature. Sensors, 17(7), 1499. https://doi.org/10.3390/s17071499

Torres-Rua, A. F., Aboutalebi, M., Nassar, A., Nieto Solana, H., Hipps, L., McKee, M.,... McKee, L. (2019). Getting closer to Landsat: Advances from the GRAPEX Project in the application of UAVs for high-resolution evapotranspiration. Proc. AGU Fall Meeting. 2019, pp. B54D-05. AGU.

Torres-Rua, A., Nieto, H., Parry, C., Elarab, M., Collatz, W., Coopmans, C.,... Kustas, W. (2018). Inter-comparison of thermal measurements using ground-based sensors, UAV thermal cameras, and eddy covariance radiometers. Proc. Autonomous Air and Ground Sensing Systems for Agricultural Optimization and Phenotyping III. 10664, p. 106640E. International Society for Optics and Photonics.

Trout, T. J., \& Bausch, W. C. (2017). USDA-ARS Colorado maize water productivity data set. Irrig. Sci., 35(3), 241-249. https://doi.org/10.1007/s00271-017-0537-9

Trout, T. J., \& Johnson, L. F. (2007). Estimating crop water use from remotely sensed NDVI, crop models and reference ET. Proc. 4th USCID Int. Conf. on Irrigation and Drainage, (pp. 275-285).

Turner, J. M. (2016). Economic potential of unmanned aircraft in agricultural and rural electric cooperatives. MS thesis. Stillwater: Oklahoma State University, Department of Agricultural Economics.

Twidwell, D., Allen, C. R., Detweiler, C., Higgins, J., Laney, C., \& Elbaum, S. (2016). Smokey comes of age: unmanned aerial systems for fire management. Front. Ecol. Environ., 14(6), 333339. https://doi.org/10.1002/fee.1299

West, G. H., \& Kovacs, K. (2017). Addressing groundwater declines with precision agriculture: An economic comparison of monitoring methods for variable-rate irrigation. Water, 9(1), 28. https://doi.org/10.3390/w9010028

Woldt, W. E., Frew, E. W., Stachura, M., Smith, J., \& Mack, J. (2015). Conducting unmanned aircraft flight operations under Federal Aviation Administration Regulations. ASABE Paper No. 152147654. St. Joseph, MI: ASABE. https://doi.org/10.13031/aim.20152147654
Woldt, W. E., Frew, E. W., \& Meyer, G. (2014). Feeding a hungry world: The potential for unmanned aircraft systems. XRDS Crossroads: The ACM for Students, 20(3), 24-27. https://doi.org/10.1145/2590599

Woldt, W. E., Nowatzki, J., Price, R., Saraswat, D., \& Weckler, P. (2016a). Taking off in new directions with unmanned aircraft: Special series on unmanned aircraft, Part 1. Resource, 23(2), 1622.

Woldt, W. E., Robbins, J., \& Saraswat, D. (2016c). Unmanned aircraft in agriculture: Exploring the opportunities, special series on unmanned aircraft - Part 3. Resource, 23(4),14-15.

Woldt, W. E., Thomasson, J. A., \& Valasek, J. ( 2016b). Unmanned aircraft systems: All types and sizes, special series on unmanned aircraft - Part 2. Resource, 23(3),18-19.

Woldt, W. E., Neale, C., Heeren, D., Frew, E. W., \& Meyer, G. E. (2018). Improving agricultural water efficiency with unmanned aircraft. Proc. Xponential, Association of Unmanned Vehicle Systems Int.

Zhang, H., \& Yemoto, K. (2019). UAS-based remote sensing of turfgrass quality, applications on the Northern Colorado Limited Irrigation Research Farm. Int. J. Precis. Agric. Aviat., 2(2), 1-10. https://doi.org/10.33440/j.ijpaa.20190202.50

Zhang, H., Han, M., Comas, L. H., DeJonge, K. C., Gleason, S. M., Trout, T. J., \& Ma, L. (2019). Response of maize yield components to growth stage-based deficit irrigation. Agron. J., 111(6), 3244-3252. https://doi.org/10.2134/agronj2019.03.0214

Zhang, Z., Cui, T. S., Liu, X. F., Zhang, Z. C., \& Feng, Z. Y. (2017). The design and implementation of 'the use of UVA in agricultural ground surveillance system'. J. Agric. Mech. Res., 39(11), 64-68.

Zhao, T. B., Niu, H., de la Rosa, E., Doll, D., Wang, D., \& Chen, Y. (2018a). Tree canopy differentiation using instance-aware semantic segmentation. ASABE Paper No. 1801699. St. Joseph, MI: ASABE. https://doi.org/10.13031/aim.201801699

Zhao, T., Yang, Y., Niu, H., Wang, D., \& Chen, Y. (2018b). Comparing U-Net convolutional network with mask R-CNN in the performances of pomegranate tree canopy segmentation. Proc. SPIE Asia-Pacific Remote Sensing. 10780, p. 107801J. SPIE. https://doi.org/10.1117/12.2325570 